\title{
TECHNO-ECONOMIC IMPACTS OF INNOVATIVE COMMERCIAL- INDUSTRIAL SCALE BIOENERGY PLANT IN PAKISTAN
}

\author{
Rizwan Rasheed ${ }^{1, *}$, Abdullah Yasar', Amtul Bari Tabinda', Naghman Khan², Yuehong Su$^{2}$ and \\ Muhammad Afzaal ${ }^{1}$
}

\author{
${ }^{1}$ Sustainable Development Study Centre, Government College University Lahore, Pakistan; \\ ${ }^{2}$ Department of Architecture and Built Environment, University of Nottingham, UK. \\ *Corresponding author's email: riz_mian@hotmail.com
}

\begin{abstract}
A case study of an innovative medium sized commercial-industrial bioenergy plant is portrayed. This plant effectively runs on various agricultural waste feedstocks like; animal-manure, vegetable, poultry and sugar wastes etc. The plant design is based on anaerobic fixed dome triple digester system connected via underground lagoon. Thus system is facilitating continuous flow of the input feedstock capacity up-to four tonnes per day. This modern scheme is built on innovation with the inclusion of mechanical stirrers, gas scrubbers, filtration, compression and storage systems. This research paper highlighted the potential techno-economic impacts of such bioenergy plant for the energy stressed small-medium industrial sector in developing countries like Pakistan. It has the capability of $142 \mathrm{MWh}$ energy generations per year; rate of return $15.42 \%$ and employment growth prospects in SME sector up-to 55\%.
\end{abstract}

Keywords: Biogas, bio-mass, renewable energy generation, energy crisis, bioenergy.

\section{INTRODUCTION}

Lives of the people of Pakistan are seriously affecting because of extreme power cuts and load-shedding. The energy supply gaps are further widening and situations are further critical in rural areas (Sahir and Qureshi, 2008; Chaudhry et al., 2009). The small-medium agro based industries of such areas are near to die because of this crisis. There is dire need for resolving such crisis in small-medium industrial setups through innovation either at individual levels or via some integrated community level approaches so to sustain the livelihoods of people (Amjid et al., 2011). Bioenergy generation can be a gifted approach in solving the acute shortages of energy in third world developing countries of South Asia like Pakistan (Shah et al., 2011). Bioenergy production has also shown tremendous potential advantages being eco-friendly and saving of resources (Petersson and Wellinger, 2009; Murphy et al., 2011). The waste digestate can also be utilized as bio-fertilizer which is rich in nutrients and suitable for the natural growth of a variety of crops (Lukehurst et al., 2010; De Meester et al., 2012). In many developing countries the commercial-farm scale fixed dome biogas plants are becoming increasingly popular (Mshandete and Parawira, 2009). It has been learnt over time that fixed dome designs are much better for anaerobic digestion than the floating dome; in fixed dome design there is much less generation of $\mathrm{CO}_{2}$ and the pressure of the biogas can also be maintained according to the required output (Bond and Templeton, 2011). The operational success and economical availability of organic feedstock like animal dung and vegetable waste etc. have driven for further innovations in the sector (Arthur et al., 2011). Medium-large industrial scale bioenergy plants can increasingly gain popularity and acceptance in a developing country like Pakistan because of huge deficit and rising cost of energy in the country (Buysman and Mol, 2013). The novel installation of a pilot $150 \mathrm{~kW}$ bioenergy plant at an industry located near Phoolnagar, district Kasur has proven quite successful, which is now leading for the practicability of similar larger projects under the self-initiative of industrial-commercial organizations (I.A. Rabbani, personal communication, November 18, 2014).

Similar commercial scale bioenergy plants can meet much of the energy demands along-with justifying the sustainability in-terms of technology, economy, environment and social developments in sub-urban and rural or even remote areas in developing countries like Pakistan. The objective of this research study is determining the viability and technoeconomic analysis of an innovative heat and/or electrical energy generation solution based on the stated pilot medium scale bioenergy plant design. That is typically designed for the industrial and commercial utility in rural and suburban Pakistan.

\section{MATERIALS AND METHODS}

A reference case based on the pilot study is modelled in this evaluation, which has been then tracked by a technoeconomic evaluation and industrial survey.

Reference case: The pilot novel bioenergy project sponsored and launched by a local industry at Phoolnagar near Lahore 
as per schematic shown in the Figure 1 (Rasheed et al. 2016); is used as a well-defined techno-economic reference scenario for the current study. The visual mediums were used to ask and recognize the acceptance and success of similar commercial projects induced by appropriate investments and chosen technology. The design parameters and technological components of the reference case project are summarized in Table 1. The reference case scenario represented a situation with an unchanged continuance of the same or similar specifications for further socio-industrial analysis.

Techno-industrial evaluation: The techno-economic analysis of the reference case was performed first of all according to design-cost factors and components summarized in Table 1. The results of the techno-economic analysis were taken into account for further socio-industrial survey, which was based on of randomly selected 100 small-medium industries at Manga-Raiwind Road and Sundar areas near Lahore. Buffalo-cow dung and vegetable-fruit waste were considered as primary inputs, whereas primary outputs have been purified biogas and electricity. End-user and industry stakeholder based common socio-industrial queries have also been embraced in the study via direct consultation with relevant stakeholders.

Key informant opinion survey: A key informant opinion protocol was designed after reconnaissance of the study area by including all the desirable factors of the techno-industrial survey. Questionnaires based on pertinent questions were developed by including the demand and supply scenarios of commercial-industrial scale bioenergy generation in the light of the reference case. Three key people from each industry were interviewed face to face i.e. a) factory owner/partner; b) site-manager/incharge; c) site engineer/technical person. Following important aspects have been covered:

General information about industry type, size, products, output volume and number of employees etc.

The Demand assessment of bioenergy production, was based on the key queries like; total working hours and number of working shifts, electricity demand and current availability, awareness about bioenergy production, willingness to pay for construction and installation of a $150 \mathrm{~kW}$ industrial bioenergy system, availability of land space for the plant, and capacity for operations, maintenance and feedstock manageability etc.

Table 1. Design parameters and main components of reference case bioenergy plant.

\begin{tabular}{ll}
\hline Description & Parameters \\
\hline Plant design & $\begin{array}{l}\text { Fixed dome-Anaerobic tri- } \\
\text { digesters wells with }\end{array}$ \\
& underground lagoon system \\
Main plant area & $620 \mathrm{~m}^{2}$ \\
Plant digesters overall useable area & $210 \mathrm{~m}^{3}$ \\
& (including lagoon)
\end{tabular}

Slurry storage tank area

Digestate storage tank area (volume)

Biogas storage cylinders area (volume)

Biogas scrubbing-filtration unit

(fibreglass reinforced polymer

material) area (volume)

Biogas compressor

Power generator set

Feedstock requirement

(cow/buffalo/poultry manure/vegetable waste)

Bioenergy output
$20.24 \mathrm{~m}^{3}$

$42.73 \mathrm{~m}^{3}$

Technological details

Continuous flow design; concreted construction with fibreglass reinforced polymer (FRP) dome covers and mechanical stirring system

Feedstock capacity; 24 tons. Temperature control $\left(35-37^{\circ} \mathrm{C}\right)$ system was installed based on hot water circulation from CHP-cooling circuit of the power generator

Concreted construction

- Do -

High strength steel material

Two stage scrubbing-filtration system; firstly water scrubbers made of $5 \mu \mathrm{m}$ FRP dish-type (inner)

filters for removal of $\mathrm{CO}_{2}$ and secondly; activated carbon and silica gel filtration mediums were employed for sulphides and water contents removal respectively. About $85-90 \%$ pure biogas has been established

2.5-3.0 MPa (400 psi approx.) Piston-2stage, stationary type and water cooled $150 \mathrm{~kW}$

(188 kVA approx.)

Natural gas (NG) gen-set; operable and run on purified biogas only for 8-10 hrs./day. Capacity of gas consumption of this generator is about 58 $\mathrm{m}^{3} / \mathrm{hr}$. $(\sim 600 \mathrm{~kJ} / \mathrm{s})$

Digester 1 was also provided with experimental microwave heating system for faster substrate decomposition

Experimented and established an average biogas output of $80 \mathrm{~m}^{3} /$ ton under the controlled conditions i.e. mechanical stirring and balanced temperature management 


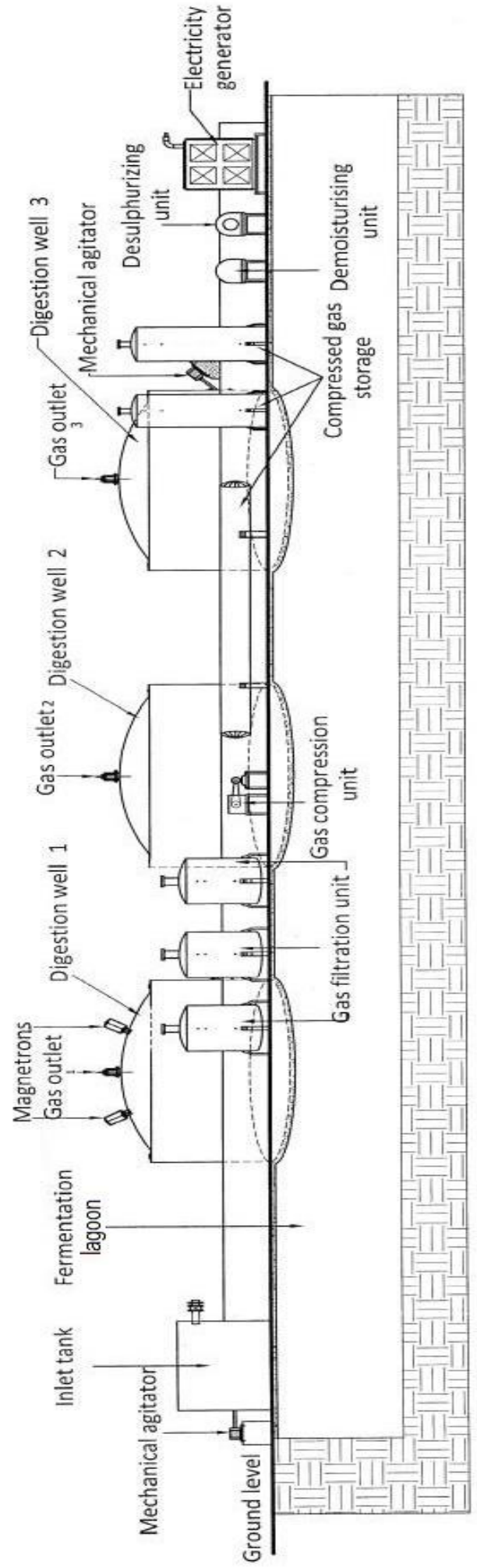

Figure 1. Schematic of reference case bioenergy plant installed at Creative Engineering Limited, Phoolnagar District Kasur (Rasheed et al., 2016).
Discussion with focus group: This is an effective qualitative research approach which enables the interviewer to act as moderator by raising some topic of debate or discussion. Research participants in a focus group are encouraged by a discussion on some pertinent issue or query or a concern (Wong, 2008). During the study period focus group deliberations were initiated among the concerned industrialcommunity people and groups belonging to different age groups, variable entrepreneurial, managerial, and supervisory to the workers class. One such study was performed in the Sundar industries which also involved the representatives of Sundar industrial association and the other one in MangaRaiwind Road industrial area where some local agrocommercial community representatives were also involved.

\section{RESULTS AND DISCUSSION}

Techno-economic analysis: The techno-economic analysis of the reference case scenario (Rasheed et al., 2016), is presented in Table 2. It portrays the cost and benefits associated with typical pilot bioenergy plant based on capital costs of technology and installations, expected life cycle, O \& $\mathrm{M}$ costs and income in-terms of energy produced.

Table 2. Techno-economic analysis of bioenergy generation from reference scenario.

\begin{tabular}{lr}
\hline Particulars & \multicolumn{1}{c}{ Value } \\
\hline Plant capital cost; technology and installations & PKR 105,00,000 \\
Expected life span* & 20 Years \\
Amortized capital-technology cost per year & PKR 525,000 \\
Operational and maintenance (O \& M) cost & PKR 2,340,000 \\
Disposal-transport cost of digestate & PKR 00 \\
Total annual cost** & PKR 2,865,000 \\
Average amount of energy produced per year & $142,380 \mathrm{kWh}$ \\
Value of energy produced per year & PKR 4,485,000 \\
Value of digestate per year & PKR 00 \\
Total annual value (income) & PKR 4,485,000 \\
Net annual benefits & PKR 1,620,000 \\
* $^{*}$ assumed on the basis of specialized civil design and quality \\
of construction.
\end{tabular}

The income-value of energy produced is calculated on the basis of cumulative average of current unit cost of utility supplied and self-generated (diesel oil generator) energy i.e. PKR 31.5 per $\mathrm{kWh}$. Results show net annual monetary benefits of PKR 1.62 Million and the net annual rate of return over the capital investment is about $15.42 \%$. These techno-economic indicators present a fairly promising picture to be replicated in-terms of other similar projects in current economic situation of the country. This is further clarified that cost and benefits regarding digestate material are not considered in the current scenario based on the fact that local market of such digestate in-terms of bio-fertilizer is 
nonexistent and nearby farmers are collecting this digestate free of cost presently. However, in future scenarios there could be additional benefits once the digestate is processed and exclusively marketed as bio-fertilizer.

Socio-industrial analysis: A sample of 100 industries was selected for socio-industrial survey and requisite analysis. Ten representative industry types as indicated in Table 3 were selected from both areas. Mean current number of employees were computed so to analyze a trend of future employment growth and increase in livelihoods if the sufficient alternate energy resources could be provided as per the demand of these industries.

Table 3. Industries selected for socio-industrial analysis at Sundar and Manga-Raiwind Road, Pakistan.

\begin{tabular}{|c|c|c|c|}
\hline $\begin{array}{l}\text { S. } \\
\text { No. }\end{array}$ & Industry Type & $\begin{array}{l}\text { Quantity of } \\
\text { Sample (no.) }\end{array}$ & $\begin{array}{l}\text { Average no. } \\
\text { of Employees }\end{array}$ \\
\hline 1 & $\begin{array}{l}\text { Textiles (Weaving and } \\
\text { Spinning) }\end{array}$ & 10 & 120 \\
\hline 2 & $\begin{array}{l}\text { Textiles (Dyeing and } \\
\text { Fabrics) }\end{array}$ & 10 & 108 \\
\hline 3 & $\begin{array}{l}\text { Textiles (Knitting and } \\
\text { Garments) }\end{array}$ & 10 & 80 \\
\hline 4 & Food and Beverages & 10 & 92 \\
\hline 5 & Pharmaceuticals & 10 & 72 \\
\hline 6 & Parts and Fabrication & 10 & 88 \\
\hline 7 & $\begin{array}{l}\text { Paper-Board and } \\
\text { Packaging }\end{array}$ & 10 & 68 \\
\hline 8 & Electrical and Electronics & 10 & 52 \\
\hline 9 & $\begin{array}{l}\text { Polymers-Chemicals and } \\
\text { Plastics }\end{array}$ & 10 & 40 \\
\hline 10 & Miscellaneous SMEs & 10 & 16 \\
\hline
\end{tabular}

Generic-need and energy supply analysis: Suburban industries in Pakistan like in Sundar and Manga-Raiwind are suffering from irregular energy supplies to acute shortages. This situation reflects the fact that industries cannot be run for more than one working shift The average energy shortages have been found out to be in the range of 5000-10000kWh per month for each industrial unit. On average the utility sources are only supplying the energy for 8-10 hours per day (i.e. 1 working shift), against the average demand of 16-20 hours per day (i.e. 2-3 working shifts), as indicated in Figure 2. Shah et al. (2011) and Awan and Khan (2014) had also described the similar findings related to energy crisis in Pakistan.

Willingness to accept-invest in medium industrial bioenergy plant: There is a dire need, willingness to accept and afford the medium scale biogas plants in these areas by all the segments of the stakeholders. $45.3 \%$ industry owners (decision makers) on average, from both suburban areas were willing to invest and own one such bio-energy plant, so to meet their rising energy requirements. However shortage of funds and/or availability of spare land were the limiting factors (Fig.3). Parawira (2009) also studied comparable parameters for development of bioenergy technology in sub-Saharan Africa.

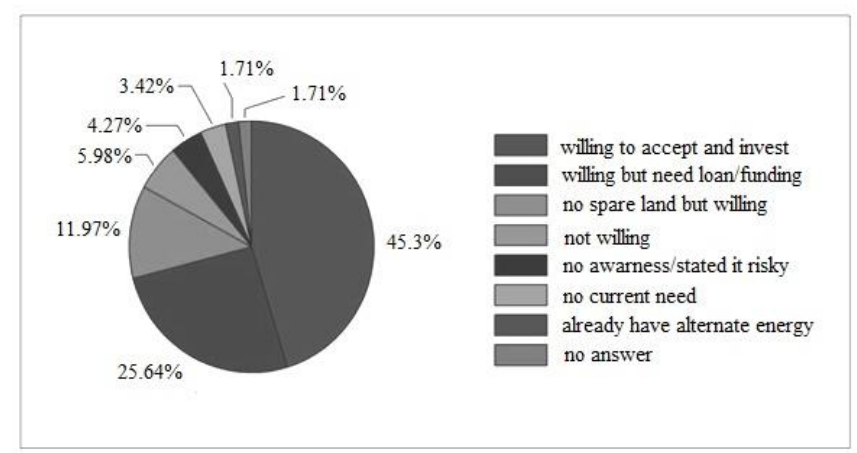

Figure 2. General Need and energy supply assessment.

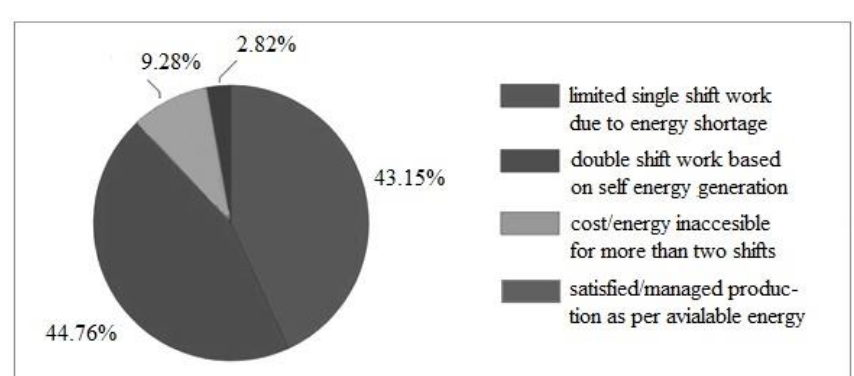

Figure 3. Willingness to accept, invest and awareness about bioenergy plant.

Manageability and willingness to pay for the feedstock: In suburban areas availability and management of the agricultural wastes in-terms of feedstock for bioenergy generation has not been an issue. Such feedstock could be economically accessible; however, their management, handling of bulk quantities, seasonal price variations and plant maintenance etc. has been unseen scenarios. Figure 4 portrays the willingness of industry owners towards operations and manageability of various feedstocks etc. for running of their prospective plants. Amigun and Blottnitz (2010) also studied related variables and had presented their finding for location and capacity and cost analyses etc. for biogas plants in Africa. Similar sort of facts were revealed under various surveys and studies in Pakistan (Amjid et al., 2015; Uddin et al., 2016).

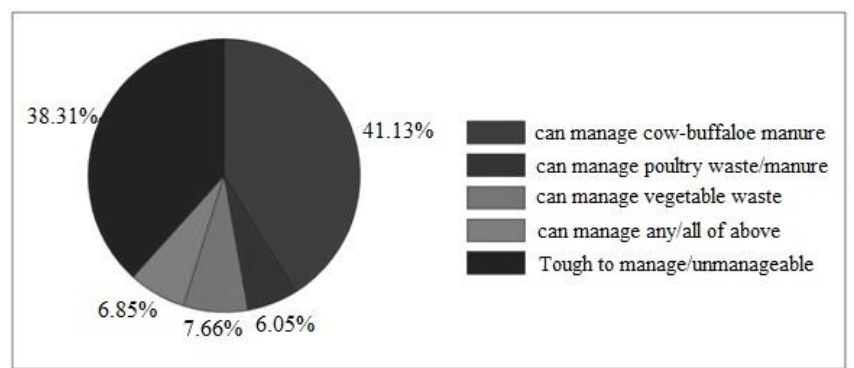

Figure 4. Capacity for operations, maintenance and feedstock manageability. 
Impacts of bioenergy on commercial and industrial growth: It was revealed during the surveys and focus group discussion with the stakeholders of both areas at Sundar and RaiwindManga Road, which many of small-cottage scale agrocommercial ventures were dead or near to shut down due to energy crisis and heavy unstructured load management by the power supplier utility. The medium-large industries are also under considerable stress due to non-availability of electricity for more than 14 hours per day. Furthermore the supply of natural gas had also extremely limited and being erratically supplied on any 1-2 days of the week which could not support any productive planning. All these scarcities caused labour layoffs and unemployment. However other survey results as portrayed in Fig.5 established that about 542,000 Nos. cattle (cows and buffaloes) were available in the vicinity pockets. Those produce about 2200 tons of manure and could be enough to run bioenergy plants of $150 \mathrm{~kW}$ for 550 smallmedium industrial units for up-to $8 \mathrm{hrs}$ per day. Industrial community and relevant stakeholders of the areas are well convinced and strongly believe that if the commercialindustrial setups will have the access for such cheaper alternate bioenergy resource they can not only revive but provisions for further growth and development of the commercial-industrial activities are highly significant. Parallel small-cottage scale vending industries shall also get established if their bioenergy projects could be funded thorough some low markup loans or interest free financing schemes. As such SME communities are keen to run and operate some joint-community scale bioenergy plant so to sustain and grow against energy shortage. Rajabapaiah et al. (1993) and Vijay et al. (1996) also reported that application of bioenergy for small-cottage scale industries had been found quite flourishing.

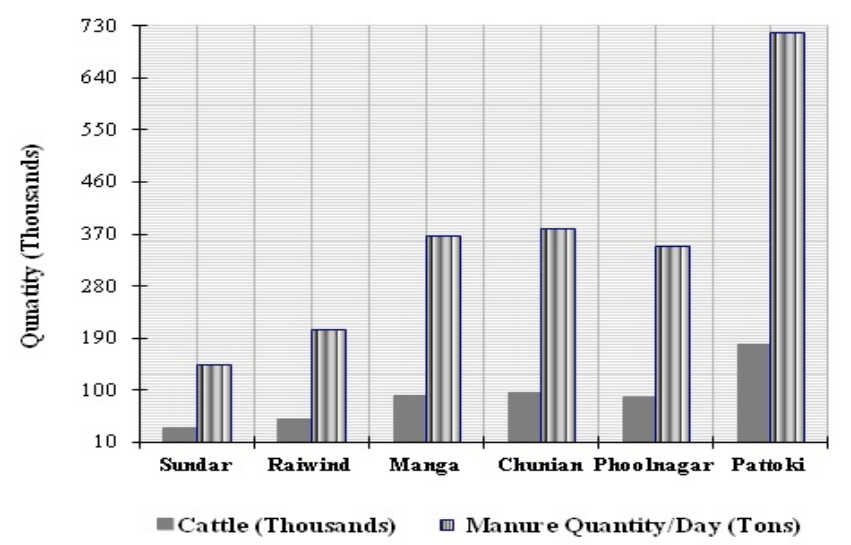

Figure 5. Survey depicting the number of cattle and manure availability in the vicinities of Sundar and Raiwind-Manga Road.

Impacts of bioenergy on livelihoods: The results of socioindustrial survey as per Table 3 clearly indicated that all most all segments of the industry are underproductive and not running up-to their full capacities because of energy shortages. The utility supplied energy has been highly insufficient, curtailed up-to 8-10 hours max and quite disruptive too in rural side industrial units. Most of the industrial units could not run their operations beyond a single shift of 8 hours as the cost of self-power generation by the industries based on diesel generators has become as costly as PKR 45.00 per $\mathrm{kWh}$. This increased the cost of production up-to 2-3 folds hence rendering the products and services noncompetitive at the market place. These factors pressurized the industries to lay-off the staff and workers, especially the unskilled and semi-skilled workers are suffering more. Resultantly they are unable to sustain their livelihoods and their income patrons are highly irregular as it has become hard for them to have a permanent or consistent employment. Commercial and rural cottage SMEs are also dying day by day hence causing further unemployment and loss of rural livelihoods.

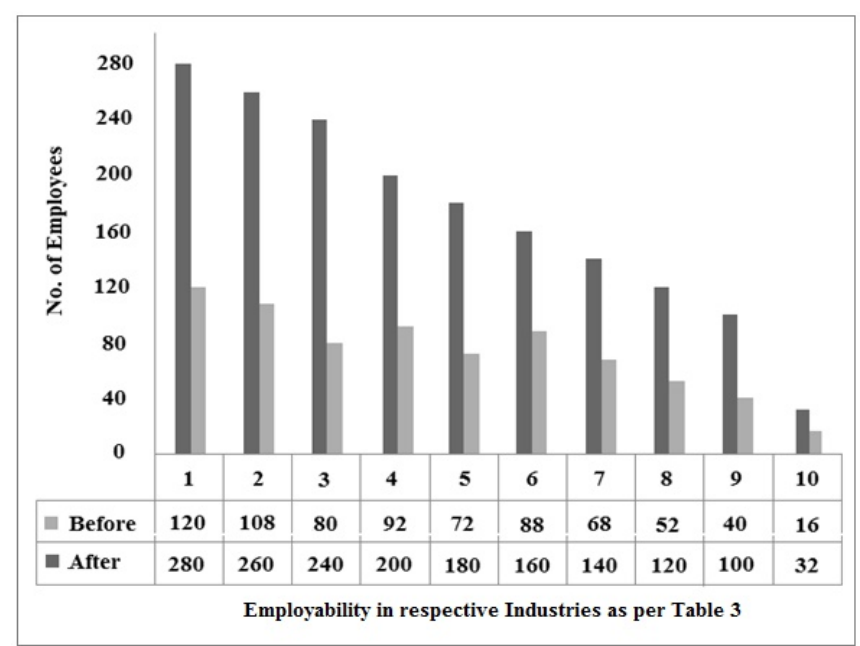

Figure 6. Capacity for employment creation and raise of livelihoods with bioenergy provision.

However, the interviews and focus group discussion with the concerned stakeholders during the survey divulged quite significant facts and figures regarding raise of employment and livelihoods in such areas if cheaper alternate bioenergy sources could be provided. It was evident from the survey results (Table 3) as analysed in Fig.6 that increased energy supplies with agro-industrial scale bioenergy plants can raise the employment levels up-to; $42.85 \%$ in textile sector, $46 \%$ in food and beverages sector, $40 \%$ in pharmaceuticals sector, $55 \%$ in parts and fabrication sector $48.57 \%$ in paper-board and packaging sector, $43.33 \%$ in electrical and electronics sector, $40 \%$ in polymers-chemicals and plastics sector and $50 \%$ in rural SMEs sector. Hence the relevant livelihoods of the people can be elevated; risks of underemployment and unemployment would be minimized resulting in the positive impacts over the society and improvement of quality of life of 
individuals. Similar advantages of commercial scale bioeneregy plants were described by Vijay et al. (1996).

Conclusions: This paper has analyzed the techno-economic potential of a modern commercial-industrial scale bioenergy plant. A reference case scenario was adapted for socioindustrial analysis, which also rendered such bioenergy plant design as win-win situation in-terms of alternate energy generation up to $142,380 \mathrm{kWh}$ per year providing the net annual benefits of PKR 1.62 million for medium scale commercial-industrial sector. This plant design is aimed at the struggling industrial sector and can be easily adapted to agricultural community based bioenergy production on a rural-village scale similar to district gas and heating found in many Scandinavian countries. It can represent a chief budge in the energy production, industrial growth, development and substantial raise of livelihoods bases on proper networking and supply chain management. Previous attempts to induce bioenergy plants in rural-agro communities have not been successful due to lack a strong supply chain and corresponding industry.

Acknowledgements: The authors wish to acknowledge support from The GC University Lahore, HEC Pakistan, and Prof. Dr. Amin U. Khan, technical and financial support from The Creative Group of Companies, Lahore Pakistan, Charles Wallace Trust and The British Council.

\section{REFERENCES}

Amigun, B. and H.V. Blottnitz. 2010. Capacity-cost and location-cost analyses for biogas plants in Africa. J. Resour. Conserv. Recy. 55:63-73.

Amjid, S.S., M.Q. Bilal, M.S. Nazir and A. Hussain. 2011. Biogas, renewable energy resource for Pakistan. Renew. Sust. Energ. Rev. 15:2833-2837.

Arthur, R., M.F. Baidoo and E. Antwi. 2011. Biogas as a potential renewable energy source: A Ghanaian case study. Renew. Energ. 36:1510-1516.

Awan, A.B. and Z.A. Khan. 2014. Recent progress in renewable energy-remedy of energy crisis in Pakistan. Renew. Sust. Energ. Rev. 33:236-253.

Bond, T. and M.R. Templeton. 2011. History and future of domestic biogas plants in the developing world. Energ. Sust. Dev. 15:347-354.

Buysman, E. and A.P. Mol. 2013. Market-based biogas sector development in least developed countries-the case of Cambodia. Energ. Policy 63:44-51.

Chaudhry, M., A.R. Raza and S.A. Hayat. 2009. Renewable energy technologies in Pakistan: Prospects and challenges. Renew. Sust. Energ. Rev. 13:1657-1662.

DeMeester, S., J. Demeyer, F. Velghe, A. Peene, H.V. Langenhove and J. Dewulf. 2012. The environmental sustainability of anaerobic digestion as a biomass valorization technology. Bioresource Technol. 121:396403.

Mshandete, A.M. and W. Parawira. 2009. Biogas technology research in selected sub-Saharan African countriesreview. Afr. J. Biotechnol. 8:116-125.

Murphy, J., R. Braun, P. Weiland and A. Wellinger. 2011. Biogas from crop digestion. IEA bioenergy task report. Available online at

http://nachhaltigwirtschaften.wsr.ac.at/iea_pdf/reports/iea_bi oenergy_task37_biogas_from_crop_digestion.pdf

Lukehurst, C.T., P. Frost and T. Al-Seadi. 2010. Utilisation of digestate from biogas plants as biofertiliser. IEA bioenergy task report. Available online at http://www.centri-force.co.uk/wpcontent/uploads/2014/07/Utilisation-of-Digestate-asBiofertiliser-V2.0.pdf

Parawira, W. 2009. Biogas technology in sub-Saharan Africa: Status, prospects and constraints. Rev. Env. Sci. Biotechnol. 8:187-200.

Petersson, A. and A. Wellinger. 2009. Biogas upgrading technologies-developments and innovations. IEA bioenergy task report. Available online at http://www.biogaspartner.de/fileadmin/biogas/Downloa ds/Studien/IEA-BiogasUpgradingTechnologies2009.pdf

Rajabapaiah, P., S. Jayakumar and A.K.N. Reddy. 1993. Biogas electricity the Pura village case study, pp.787817. In: T.B. Johnson, H. Kelly, A.K.N. Reddy and R.H. Williams (eds.), Renewable Energy Sources for Fuel and Electricity. Earth Scan, London.

Rasheed, R., N. Khan, A. Yasar, Y. Su and A.B. Tabinda. 2016. Design and cost-benefit analysis of a novel anaerobic industrial bioenergy plant in Pakistan. Renew. Energ. 90:242-247.

Sahir, M.H. and A.H. Qureshi. 2008. Assessment of new and renewable energy resources potential and identification of barriers to their significant utilization in Pakistan. Renew. Sust. Energ. Rev. 12:290-298.

Shah, A.A., S.M. Qureshi, A. Bhutto and A. Shah. 2011. Sustainable development through renewable energy-the fundamental policy dilemmas of Pakistan. Renew. Sust. Energ. Rev. 15:861-865.

Uddin, W., B. Khan, N. Shaukat, M. Majid, G. Mujtaba, A. Mehmood, S.M. Ali, U. Younas, M. Anwar and A.M. Almeshal. 2016. Biogas potential for electric power generation in Pakistan: A survey. Renew. Sust. Energ. Rev. 54:25-33.

Vijay, V.K., R. Prasad, J.P. Singh and V.P.S. Sorayan. 1996. A case for biogas energy application for rural industries in India. Renew. Energ. 9:993-996.

Wong, L.P. 2008. Focus group discussion: A tool for health and medical research. Singapore Med. J. 49:256-60. 